\title{
A regulação do acesso à atenção especializada e a Atenção Primária à Saúde nas políticas nacionais do SUS
}

\author{
I ${ }^{1}$ Eduardo Alves Melo, ${ }^{2}$ Gustavo Graça Gomes, ${ }^{3}$ Jacqueline Oliveira de Carvalho, \\ ${ }^{4}$ Pedro Henrique Braga Pereira, ${ }^{5}$ Kennedy Pereira de Lima Guabiraba I
}

Resumo: Diferentes formulaçóes têm dado destaque à Atenção Primária à Saúde como porta de entrada preferencial do sistema de saúde, base das redes de atenção e função de coordenação do cuidado. A regulação assistencial (ou do acesso), por sua vez, vem sendo considerada, no Brasil, uma estratégia e tecnologia central de gestấo das redes. Este artigo objetivou caracterizar a interface entre atenção primária e regulação assistencial nas formulaçóes e diretrizes nacionais sobre regulação assistencial do SUS, considerando o período de 2002 a 2017. Adotou-se a metodologia da análise documental, utilizando fontes de domínio público, notadamente portarias e manuais técnicos do Ministério da Saúde, organizando os conteúdos extraídos nas dimensôes "conceitos de regulação", "organização e gestão da regulação" e "estratégias e ferramentas de regulação", dentro das quais se buscou caracterizar o lugar da atenção primária. Observou-se maior destaque para a interface entre regulação assistencial ambulatorial e atenção primária a partir de 2011 com a noção de microrregulação, de modo mais marcante nos documentos e iniciativas relacionados à gestão da atenção primária do que nos específicos da regulação, enfocando a elaboração de dispositivos de regulação a partir da atenção primária, destacando-se o Telessaúde.

> Palavras-chave: regulação do acesso; atenção primária à saúde; políticas de saúde.

\author{
${ }^{1}$ Fundação Oswaldo Cruz. Rio de \\ Janeiro-RJ, Brasil; Universidade \\ Federal Fluminense. Niterói-RJ, \\ Brasil (eduardo.melo@ensp. \\ fiocruz.br). \\ ORCID: 0000-0001-5881-4849 \\ 2 Fundação Oswaldo Cruz. \\ Rio de Janeiro-RJ, Brasil \\ (gustavogracagomes@yahoo. \\ com.br). \\ ORCID: 0000-0001-5608-0183 \\ ${ }^{3}$ Fundação Oswaldo Cruz. Rio \\ de Janeiro-RJ, Brasil (jacqueline. \\ carvalhorj@gmail.com). \\ ORCID: 0000-0003-2706-0508 \\ ${ }^{4}$ Fundação Oswaldo Cruz. \\ Rio de Janeiro-RJ, Brasil \\ (pedrobragamfc@gmail.com). \\ ORCID: 0000-0003-2559-8312 \\ ${ }^{5}$ Universidade Federal \\ Fluminense. Niterói-RJ, Brasil \\ (kennedyguabiraba@gmail.com) \\ ORCID: 0000-0001-7658-8689
}

Recebido em: 18/06/2020 Aprovado em: 07/12/2020 Revisado em: 23/01/2021 


\section{Introdução}

Diferentes formulaçôes sobre as Redes de Atenção à Saúde (RAS) têm dado destaque à Atenção Primária à Saúde (APS) como porta de entrada preferencial no sistema de saúde e função de coordenação do cuidado (STARFIELD, 2002; MENDES, 2010; MAGALHÂES JR, 2014). No entanto, um dos desafios à coordenação do cuidado na APS brasileira diz respeito à interação e continuidade do cuidado entre diferentes serviços das RAS, notadamente entre APS e atenção especializada (MAGALHĀES JR; PINTO, 2014; FAUSTO et al., 2014).

O acesso à atenção especializada (ambulatorial e hospitalar), por sua vez, é um dos maiores problemas do SUS, decorrendo tanto da insuficiente oferta de ações diagnósticas e terapêuticas (dependendo da especialidade e da localização geográfica) quanto dos modos de financiamento, organização e funcionamento da atenção especializada (AE) e de outros elementos das RAS, como por exemplo a qualidade de encaminhamentos e solicitaçóes (de exames, consultas, procedimentos) (SOLLA; REIS, 2008; ROCHA, 2014; TESSER; POLI, 2017). A partir de crítica ao trabalho isolado e fragmentado dos especialistas e aos limites das políticas voltadas à atenção especializada, alguns autores têm proposto modelos matriciais como forma de reorganização do trabalho dos profissionais que atuam em ambulatórios de especialidades, em relação de suporte e mais próxima à APS, buscando diminuir a fragmentação e as interrupções no cuidado entre serviços. (CAMPOS; DOMITTI, 2007; GRIMSHAW et al., 2008; TESSER; POLI, 2017).

A regulação é um conceito polissêmico e frequentemente se refere a relaçóes estabelecidas pelo Estado com o mercado (OLIVEIRA; ELIAS, 2012). No Brasil, em que pese a existência de açóes regulatórias antes do SUS (SANTOS; MERHY, 2006), estas passam a ter mais visibilidade e consistência na década de 2000 , inclusive com a separação entre regulaçáo geral do sistema de saúde e a que incide sobre a operação cotidiana do sistema por meio de regras, dispositivos e ferramentas para operar a assistência (MAGALHÁES JR, 2006; OLIVEIRA, 2006). Em diferentes conformaçôes da regulação assistencial (ou do acesso) no Brasil (ambulatorial, urgências, leitos), princípios e diretrizes como equidade, transparência, utilização adequada e tempo oportuno de acesso (com base nas necessidades dos usuários), visando à integralidade do cuidado, têm sido evocados. Isto também tem levado 
em conta os custos crescentes do setor saúde, o subfinanciamento do SUS, uma certa racionalização do uso de recursos, as lacunas na oferta de açóes e serviços e problemas na organização e gestão do acesso às ofertas públicas e privadas contratadas (BARBOSA et al., 2016; VILARINS et al., 2012).

Nos arranjos de regulação do acesso, destacam-se as centrais de regulação e complexos reguladores, configurando-se como espaços privilegiados de observaçáo e gestão de ofertas do conjunto do sistema (ou das RAS em municípios, regiôes de saúde e estados), com visão mais abrangente do que aquela que se costuma ter em cada serviço de saúde. No entanto, inclusive pela aposta feita na APS enquanto espaço privilegiado de acesso e de coordenação do cuidado, tem havido críticas e recomendaçóes de que a regulação assistencial seja compartilhada com o espaço local dos serviços, não se restringindo às centrais de regulação (ALBIERI; CECILIO, 2015; BADUY, 2011; GIANNOTTI, 2013; OLIVEIRA, 2016; PINTO et al., 2017).

Os problemas e desafios mencionados na organização da atenção especializada (incluindo o acesso), bem como na efetiva capacidade de coordenação do cuidado pela APS se intersectam com os processos de regulação assistencial, além de nos remeterem aos alcances e limites das próprias formulaçôes e diretrizes federais neste campo. Em virtude do exposto, o objetivo deste artigo é caracterizar a interface entre regulação do acesso à atenção especializada e APS, nas políticas e iniciativas nacionais do SUS, considerando o período de 2002 a 2017.

\section{Metodologia}

Trata-se de estudo descritivo de base qualitativa. A metodologia utilizada foi a análise documental, que, em pesquisa qualitativa, tem como resultado a conversão de um material primário em um secundário, a partir da extração de elementos informativos de um documento original, com o objetivo de expressar seu conteúdo de maneira abreviada (KRIPKA et al., 2015).

No presente estudo, trata-se de uma análise de documentos de políticas nacionais do SUS. A este respeito, refletindo sobre as políticas públicas, Mattos e Baptista (2011) apontam alcances e limites da análise de documentos oficiais, considerados como uma importante expressão ou face das políticas, mas que não nos permite entender, por exemplo, como o SUS funciona na prática, pois pode haver diferenças marcantes entre o que se enuncia e o que se faz, tendo em vista as múltiplas 
realidades e interesses que compóem os projetos políticos. Melo et al. (2018), por sua vez, indicam a necessidade de diferenciar, no conteúdo dos documentos oficiais, elementos conceituais, recomendaçôes e dispositivos concretos de indução, além de estabelecer relaçóes entre documentos e com o contexto.

Neste trabalho, foram selecionadas fontes de domínio público que ajudam a contextualizar a regulaçáo do acesso à atenção especializada e sua interface com a Atenção Primária à Saúde nas políticas nacionais do SUS, relativas ao período de 2002 a 2017. Visando caracterizar elementos mais teórico-conceituais e abertos (como entendimentos e recomendaçóes), bem como dispositivos indutores e operacionais presentes nos materiais analisados, os resultados do estudo foram organizados em torno das dimensôes "noçôes e conceitos de regulação", "organização e gestão da regulação" e "estratégias e ferramentas de regulação", dentro das quais se buscou caracterizar o lugar da Atenção Primária à Saúde.

Este estudo dispensou avaliação de comitê de ética, dado se tratar de análise de fontes documentais de domínio público. Os autores assumem a responsabilidade pelas análises realizadas.

\section{Resultados}

\section{Breve caracterizaçáo dos documentos}

Os documentos selecionados possuem diferentes naturezas: enquanto alguns configuram-se como políticas, outros têm caráter técnico-operacional. Apresentamse especialmente nos formatos de portaria e de manuais. O quadro 1 apresenta os documentos estudados, o ano de suas publicações e uma indicação genérica dos seus elementos. Pode-se perceber que alguns documentos são específicos sobre regulação, ao passo que a maioria aborda também outros temas. 
Quadiro 1. Caracterizaçấo dos documentos analisados

\begin{tabular}{|c|c|c|}
\hline Documento & $\begin{array}{c}\text { Ano de } \\
\text { publicaçáo }\end{array}$ & Elementos centrais \\
\hline NOAS & 2002 & $\begin{array}{l}\text { Instituída pela Portarias do Ministério da Saúde no } 373 / 2002 \\
\text { (NOAS-SUS 2002), amplia a atribuição dos municípios na atenção } \\
\text { básica, estabelece a regionalização para hierarquização de serviços e } \\
\text { maior equidade, cria mecanismos de gestão do SUS e atualiza critérios } \\
\text { de habilitação de Estados e Municípios. }\end{array}$ \\
\hline $\begin{array}{l}\text { Pacto pela } \\
\text { saúde }\end{array}$ & 2006 & $\begin{array}{l}\text { Formalizado pela Portaria GM/MS no } 399 / 2006 \text { e firmado pelas três } \\
\text { esferas de gestão do SUS, anuncia novos processos e instrumentos de } \\
\text { gestão visando maior efetividade, eficiência e qualidade das respostas } \\
\text { e redefine responsabilidades coletivas, possuindo três dimensóes: } \\
\text { Pactos Pela Vida, em Defesa do SUS e de Gestáo. }\end{array}$ \\
\hline $\begin{array}{l}\text { Política } \\
\text { Nacional de } \\
\text { Atenção Básica }\end{array}$ & $\begin{array}{l}2006,2011 \\
\text { e } 2017\end{array}$ & $\begin{array}{l}\text { Em formato de portaria, possui três versões, que estabelecem e/ou } \\
\text { revisam diretrizes e normas para a organizaçâo da atenção primária. }\end{array}$ \\
\hline $\begin{array}{l}\text { Política } \\
\text { Nacional de } \\
\text { Regulação }\end{array}$ & 2008 & $\begin{array}{l}\text { Criada pela portaria GM/MS no } 1.559 / 2008 \text {, institui a Política } \\
\text { Nacional de Regulação do SUS como instrumento para a assunçáo } \\
\text { plena de responsabilidades sanitárias pelas esferas de governo. }\end{array}$ \\
\hline $\begin{array}{l}\text { Diretrizes para } \\
\text { a implantaçáo } \\
\text { de complexos } \\
\text { reguladores }\end{array}$ & $\begin{array}{l}2010\left(2^{\mathrm{a}}\right. \\
\text { edição) }\end{array}$ & $\begin{array}{l}\text { Manual da série Pactos pela Saúde 2006, publicado pelo Ministério } \\
\text { da Saúde em 2010. Orienta os gestores na conformaçáo do processo } \\
\text { regulatório, apresentando conceitos e estratégias para a regulação do } \\
\text { acesso a ser efetivada com a implantaçáo dos Complexos Reguladores. }\end{array}$ \\
\hline $\begin{array}{l}\text { Portaria } \\
\mathrm{n}^{\circ} 2.554 \text { - } \\
\text { Telessaúde }\end{array}$ & 2011 & $\begin{array}{l}\text { Institui, no Programa de Requalificação de Unidades Básicas de } \\
\text { Saúde, o componente de informatização e Telessaúde Brasil Redes na } \\
\text { atenção primária. }\end{array}$ \\
\hline $\begin{array}{l}\text { Portarias } \mathrm{n}^{\circ} \\
2.859 \text { e } 2.860 \\
\text { - Telessaúde }\end{array}$ & 2014 & $\begin{array}{l}\text { A primeira institui regras relativas ao subsídio mensal destinado aos } \\
\text { Núcleos Intermunicipais e Estaduais de Telessaúde Brasil Redes. } \\
\text { A segunda define os valores do custeio aos Núcleos de Telessaúde } \\
\text { Brasil Redes. }\end{array}$ \\
\hline $\begin{array}{l}\text { Manual } \\
\text { instrutivo } \\
\text { Telessaúde }\end{array}$ & 2015 & $\begin{array}{l}\text { Manual instrutivo lançado pelo Ministério da Saúde, orienta sobre } \\
\text { a habilitaçáo dos Núcleos de Telessaúde ao recebimento do custeio } \\
\text { mensal, esclarecendo os indicadores a serem monitorados. }\end{array}$ \\
\hline
\end{tabular}

Fonte: elaboração dos autores

\section{Noçóes e conceitos de regulação assistencial}

Ao longo dos anos, podem ser observadas continuidades e agregaçóes nos conceitos de regulação presentes nas políticas e iniciativas nacionais. A NOAS 2002 define a regulação assistencial como o principal instrumento na busca da 
alternativa assistencial mais adequada à necessidade do cidadão de forma organizada, qualificada, oportuna e equânime. Apresenta-se o termo médico regulador e a qualificação de autoridade sanitária dada a este ator, além de se atribuir à APS a responsabilidade na garantia de acesso a consultas e exames complementares inerentes ao tratamento de algumas condiçôes de saúde.

O Pacto pela Saúde, de 2006, descreve a regulação como uma das diretrizes para a gestão do SUS e define a regulação do acesso à assistência (ou regulação assistencial) como: "conjunto de relaçôes, saberes, tecnologias e açôes que intermedeiam a demanda dos usuários por serviços de saúde e o acesso a estes”. Reforça a organização e funcionamento da rede a partir das necessidades apresentadas pela APS, bem como a integração desta com o conjunto do sistema.

No mesmo ano, a primeira Política Nacional de Atenção Básica (PNAB) é publicada. Apesar de não trazer uma conceituação acerca da regulação do acesso, estabelece competências às Secretarias Municipais de Saúde e ao Distrito Federal no que tange à organizaçáo do fluxo de usuários, visando a garantia das referências a serviços e açóes de saúde fora do âmbito da APS. Atribui como atividade específica ao profissional médico da equipe de Saúde da Família, o encaminhamento, quando necessário, de usuários a serviços de média e alta complexidade, respeitando fluxos de referência e contrarreferência locais, mantendo sua responsabilidade pelo acompanhamento do plano terapêutico do usuário.

Publicada em 2008, a Política Nacional de Regulação apresenta-se formalmente em resposta à necessidade de estruturação das ações de regulação, fortalecimento dos instrumentos de gestão do SUS e do processo de regionalização, incluindo a integração de ações e serviços de saúde com objetivo de garantir a organização das redes e fluxos assistenciais. Organiza três dimensóes da regulação, sendo elas: Regulação de Sistemas de Saúde, que define as macrodiretrizes para a Regulação da Atenção à Saúde. Esta, por sua vez, tem como foco a organização da rede de serviços. Por último, a Regulação do acesso à assistência (também chamada de regulação assistencial) tem como cerne a organização, o controle, o gerenciamento e a priorização do acesso e dos fluxos assistenciais no âmbito do SUS, tendo os gestores públicos seu ator central e a regulação médica como autoridade sanitária.

Assim como normativas anteriores (BRASIL, 2002; 2006), ratifica o processo de regulação do acesso a partir da APS a fim de disponibilizar a oferta assistencial mais adequada à necessidade de saúde do cidadão através de mecanismos como 
a regulação médica da atenção ambulatorial à hospitalar, controle de leitos, padronização de solicitaçóes e estabelecimento de referências entre unidade de diversos níveis de atenção à saúde.

No manual Diretrizes para implantação de complexos reguladores, de 2010, a importância da regulação é descrita pela necessidade de qualificação do acesso, otimização dos recursos e reforço das funçôes de gestão. Segundo este documento, "na prática, a ação regulatória é definida como o processo de operacionalização, monitoramento e avaliação da solicitação de procedimentos, realizada por um profissional de saúde, levando em conta a classificação de risco, o cumprimento de protocolos de regulaçáo estabelecidos para disponibilizar a alternativa assistencial mais adequada" (BRASIL, 2010). Aponta-se que todos os municípios devem organizar uma APS resolutiva que faça solicitaçóes padronizadas pelos protocolos aos demais níveis de complexidade. No manual indica-se também que a regulação deve enfrentar a questão da demanda real e da demanda artificial considerando a oferta potencial e a oferta existente.

Na PNAB 2011 aparece o termo microrregulação, como uma regulação a ser realizada pelos profissionais da atenção básica, que deve ocorrer de maneira articulada aos processos regulatórios em outros espaços da rede. Aponta-se que, dessa forma, permite-se o aumento da qualidade da regulaçáo e o acesso a outros pontos de atenção, nas condiçôes e no tempo adequado, com equidade. Ainda no ano de 2011, a Portaria no 2.554 institui o componente de Informatização Telessaúde Brasil Redes na Atenção Básica com o objetivo de ampliar sua resolutividade e integração com a RAS. Essa normativa fala em dotar as unidades básicas de saúde com equipamentos de informática, articulando o Telessaúde com a rede e a regulação da oferta de serviços.

As portarias no 2.859 e 2.860 , de 2014, não trazem noçóes de regulação, mas reafirmam o compromisso de ampliação da resolutividade da APS, com incentivos relacionados ao uso Telessaúde e à sua articulação com a Regulação.

O documento intitulado Custeio dos Núcleos de Telessaúde Brasília - Manual instrutivo, de 2015, considera a regulação como tecnologia de gestão com função de ordenar o acesso às açôes e serviços de saúde, para um atendimento com indicação e no tempo certo, priorizando casos a partir de fatores como risco, necessidade e vulnerabilidade. Há também a noção da organização da atenção em saúde a partir de linhas de cuidado, de maneira a qualificar a atençáo e servir de referência para o processo de regulação, assim como os protocolos de encaminhamento. 
A PNAB de 2017, por sua vez, valoriza a regulação para defender o uso racional dos recursos em saúde, de maneira a impedir deslocamentos desnecessários e trazer maior eficiência e equidade à gestáo das listas de espera. Considera processos microrregulatórios, o matriciamento aparece como ferramenta para potencializar a resolução de casos no âmbito da APS e o Telessaúde compóe um articulado conjunto de suporte às decisões clínicas e aos processos de regulação do acesso.

No quadro 2, são sintetizados os principais conceitos e noções sobre regulação presentes nas políticas estudadas.

Quadiro 2. Noçóes e conceitos de regulação nas políticas nacionais de saúde de 2002 a 2017

\begin{tabular}{|c|c|c|c|}
\hline Documento & $\begin{array}{c}\text { Ano de } \\
\text { publicaçáo }\end{array}$ & $\begin{array}{c}\text { Principais noçóes e conceitos } \\
\text { de regulação }\end{array}$ & $\begin{array}{c}\text { Lugar da APS no conceito } \\
\text { identificado }\end{array}$ \\
\hline NOAS & 2002 & $\begin{array}{l}\text { Indica a regulação da assistência } \\
\text { como alternativa assistencial } \\
\text { mais adequada à necessidade do } \\
\text { cidadão, de forma equânime, } \\
\text { ordenada, oportuna e qualificada. }\end{array}$ & $\begin{array}{l}\text { Define como responsabilidade e } \\
\text { ação estratégica mínimas da APS } \\
\text { o acesso à referência hospitalar e } \\
\text { ambulatorial especializada quando } \\
\text { necessária, com ênfase especial na } \\
\text { assistência à saúde infantil. }\end{array}$ \\
\hline $\begin{array}{l}\text { Pacto pela } \\
\text { saúde }\end{array}$ & 2006 & $\begin{array}{l}\text { Regulação do acesso à saúde } \\
\text { definida como um conjunto } \\
\text { de saberes, tecnologias e ações } \\
\text { nas relações entre demanda dos } \\
\text { usuários e o seu acesso à saúde. }\end{array}$ & $\begin{array}{l}\text { Orienta a organização e } \\
\text { a pactuação da rede pelas } \\
\text { necessidades da APS, através } \\
\text { da integração e articulação dos } \\
\text { serviços de atenção básica com os } \\
\text { demais níveis do sistema. }\end{array}$ \\
\hline $\begin{array}{l}\text { PNAB } \\
2006\end{array}$ & 2006 & $\begin{array}{l}\text { Não apresenta noçóes e conceitos } \\
\text { de regulação, embora indique } \\
\text { necessidade de organização do } \\
\text { fluxo de usuários para a garantia } \\
\text { das referências a serviços e açóes } \\
\text { de saúde fora da APS pelos } \\
\text { municípios. }\end{array}$ & $\begin{array}{l}\text { Especifica o encaminhamento } \\
\text { de usuários a serviços de } \\
\text { maior complexidade pelo } \\
\text { profissional médico da equipe } \\
\text { de Saúde da Família, mantendo } \\
\text { sua responsabilidade pelo } \\
\text { acompanhamento terapêutico do } \\
\text { usuário. }\end{array}$ \\
\hline $\begin{array}{l}\text { Política } \\
\text { Nacional de } \\
\text { Regulaçáo }\end{array}$ & 2008 & $\begin{array}{l}\text { Diferencia regulação em } 3 \text { tipos: } \\
\text { do sistema, da atenção e do } \\
\text { acesso/assistencial. A última com } \\
\text { foco no controle, organização, no } \\
\text { gerenciamento e na priorização do } \\
\text { acesso. }\end{array}$ & $\begin{array}{l}\text { Orienta a regulação do acesso } \\
\text { a partir da APS, provendo } \\
\text { capacitação, ordenação de } \\
\text { fluxo, aplicação de protocolos e } \\
\text { informatização. }\end{array}$ \\
\hline
\end{tabular}




\begin{tabular}{|c|c|c|c|}
\hline Documento & $\begin{array}{c}\text { Ano de } \\
\text { publicaçáo }\end{array}$ & $\begin{array}{c}\text { Principais noçóes e conceitos } \\
\text { de regulaçáo }\end{array}$ & $\begin{array}{l}\text { Lugar da APS no conceito } \\
\text { identificado }\end{array}$ \\
\hline $\begin{array}{l}\text { Diretrizes } \\
\text { para a } \\
\text { implantação } \\
\text { de } \\
\text { complexos } \\
\text { reguladores }\end{array}$ & 2010 & $\begin{array}{l}\text { Apresenta a regulação como } \\
\text { instrumento para qualificar o } \\
\text { acesso e otimizar recursos pelo uso } \\
\text { de protocolos e da estratificação } \\
\text { de riscos. Utiliza termos como } \\
\text { demanda real, demanda artificial, } \\
\text { oferta potencial e oferta existente. }\end{array}$ & $\begin{array}{l}\text { Aponta que todos os municípios } \\
\text { devem organizar uma APS } \\
\text { resolutiva que faça solicitaçôes } \\
\text { padronizadas pelos protocolos aos } \\
\text { demais níveis de complexidade. }\end{array}$ \\
\hline PNAB 2011 & 2011 & $\begin{array}{l}\text { Utiliza a noção de } \\
\text { "microrregulaçáo" como práticas } \\
\text { de regulação exercidas pelos } \\
\text { profissionais da APS, além dos } \\
\text { processos de regulação executados } \\
\text { pelas centrais. }\end{array}$ & $\begin{array}{l}\text { Orienta a articulação das } \\
\text { práticas de regulação realizadas } \\
\text { na atençáo básica com os } \\
\text { processos regulatórios realizados } \\
\text { em outros espaços da rede, de } \\
\text { modo a permitir a qualidade da } \\
\text { microrregulação e o acesso a outros } \\
\text { pontos de atenção. }\end{array}$ \\
\hline $\begin{array}{l}\text { Portaria } \\
n^{\circ} 2.554 \text { - } \\
\text { Telessaúde }\end{array}$ & 2011 & $\begin{array}{l}\text { Não apresenta noçóes e conceitos } \\
\text { de regulaçáo. }\end{array}$ & $\begin{array}{l}\text { Indica o desenvolvimento de ações } \\
\text { de telessaúde, o apoio matricial, a } \\
\text { formação e a educação permanente } \\
\text { de forma integrada com outros } \\
\text { pontos da Rede de Atenção à } \\
\text { Saúde para qualificação das ações e } \\
\text { serviços ofertados pela APS. }\end{array}$ \\
\hline $\begin{array}{l}\text { Portarias } \\
n^{\circ} 2.859 \\
\text { e } 2.860 \text { - } \\
\text { Telessaúde }\end{array}$ & 2014 & $\begin{array}{l}\text { Não apresentam noçóes e conceitos } \\
\text { novos ou diferentes de regulação. }\end{array}$ & $\begin{array}{l}\text { Não apresentam noçôes e conceitos } \\
\text { novos ou diferentes de regulação. }\end{array}$ \\
\hline $\begin{array}{l}\text { Manual } \\
\text { Instrutivo } \\
\text { Telessaúde }\end{array}$ & 2015 & $\begin{array}{l}\text { Considera a regulação como } \\
\text { tecnologia de gestão com função } \\
\text { de ordenar o acesso às açóes } \\
\text { e serviços de saúde, para um } \\
\text { atendimento com indicaçáo e no } \\
\text { tempo certo, priorizando casos } \\
\text { a partir de fatores como risco, } \\
\text { necessidade e vulnerabilidade }\end{array}$ & $\begin{array}{l}\text { Aponta o Telessaúde como } \\
\text { estratégia para a ampliar e } \\
\text { facilitar o acesso a determinadas } \\
\text { açóes de saúde, aumentar a } \\
\text { resolutividade na Atençáo Básica, } \\
\text { realizar matriciamento e ser } \\
\text { uma ferramenta de educação } \\
\text { permanente. }\end{array}$ \\
\hline
\end{tabular}

continua... 


\begin{tabular}{|l|c|l|l|}
\hline Documento & $\begin{array}{c}\text { Ano de } \\
\text { publicaçáa }\end{array}$ & \multicolumn{1}{|c|}{$\begin{array}{c}\text { Principais noçóes e conceitos } \\
\text { de regulaçáo }\end{array}$} & \multicolumn{1}{c|}{$\begin{array}{c}\text { Lugar da APS no conceito } \\
\text { identificado }\end{array}$} \\
\hline PNAB & 2017 & $\begin{array}{l}\text { Apresenta como objetivo da } \\
\text { regulaçáo a organizaçáo do acesso, } \\
\text { induzindo ao uso racional de } \\
\text { recursos em saúde, impedindo } \\
\text { deslocamentos desnecessários } \\
\text { e trazendo maior eficiência e } \\
\text { equidade à gestáo das listas de } \\
\text { espera. }\end{array}$ & $\begin{array}{l}\text { Recomenda o aumento da } \\
\text { capacidade clínica das equipes } \\
\text { e fortalecimento das práticas } \\
\text { de microrregulação. Inclui } \\
\text { como atribuiçấo do ACS no } \\
\text { acompanhamento das necessidades } \\
\text { dos usuários no que diz respeito a } \\
\text { agendamentos ou desistências de } \\
\text { consultas e exames solicitados }\end{array}$ \\
\hline
\end{tabular}

Fonte: elaboração dos autores.

\section{Organização e gestáo da regulação assistencial}

$\mathrm{Na}$ NOAS 2002, a regulaçáo aparece junto com o controle e a avaliaçáa, devendo ser coerente com os processos de planejamento, programação e alocação de recursos em saúde. A política amplia formalmente as responsabilidades dos municípios na APS e busca constituir o processo de regionalização como estratégia de hierarquização dos serviços de saúde e de busca por maior equidade.

O documento indica a implantação de complexos reguladores para a efetivação da regulação da assistência. Nesses complexos, a regulação das urgências, consultas, leitos e outros estariam em unidades de trabalhos responsáveis por sua efetivação de forma equânime, ordenada, oportuna e qualificada. Destaca-se também a delegação de autoridade sanitária ao médico regulador pelo gestor competente, para que exerça responsabilidade sobre a regulação da assistência, instrumentalizada por protocolos técnico-operacionais.

Na redefinição de responsabilidades promovida pelo Pacto Pela Saúde, destaca-se no papel dos municípios, a organização e pactuação do acesso a açóes e serviços de atenção especializada a partir da atenção básica por meio de processos de integração e articulação entre os níveis do sistema com base na Programação Pactuada Integrada (PPI). Também ficam responsáveis por operar o complexo regulador dos serviços presentes no seu território, de acordo com a pactuação estabelecida, realizando a cogestão com o Estado e outros municípios, das referências intermunicipais.

Destaca-se a função da União de estruturação da política nacional de regulação da atenção à saúde, além de ter uma posição de estimular e apoiar municípios e estados, coordenando e monitorando os processos de regulação. Em relação aos 
estados, notam-se os papéis de apoiar os municípios e operar centrais de regulação estaduais, conforme pactuação. A PNAB 2006 apresenta poucos elementos sobre a organização e gestão da regulação. Coloca-se a garantia dos fluxos de referência e contrarreferência aos serviços especializados como um item necessário às açôes de atenção primária nos municípios.

A Política Nacional de Regulação, de 2008, define os modelos de estrutura e abrangência dos complexos reguladores municipais, regionais e estaduais, a serem pactuados pelos gestores. Além disso, o documento apresenta as atribuições da União, estados e municípios em seus âmbitos administrativos, no tocante à regulação, mantendo as formulações do Pacto Pela Saúde. Há poucas menções ao lugar da APS na arquitetura organizativa e gerencial da regulação.

Outros aspectos importantes relativos à gestão e organização da regulação foram elaborados em 2010, na segunda edição do documento Diretrizes para implantação de complexos reguladores, como detalhes da estruturação do complexo regulador, especificando desde seu quadro profissional até detalhes da infraestrutura mínima necessária para implantação e funcionamento adequado do mesmo. Além disso, defende-se que os municípios devem organizar uma atenção primária resolutiva que faça solicitaçóes padronizadas pelos protocolos aos outros níveis de complexidade.

$\mathrm{Na}$ PNAB 2011 coloca-se a atenção primária como coordenadora do cuidado e ordenadora das redes, atuando como um centro de comunicação entre os pontos de atenção, mas não se aprofunda em questôes relativas à organização e gestão geral da regulação. Basicamente indica a necessidade de compatibilizar a microrregulação local com aquela exercida nas centrais.

A Portaria no 2.554 , do Telessaúde, não detalha elementos organizativos e de gestão específicos sobre regulação, embora preveja organização interna do Telessaúde visando ampliar a resolutividade da APS e refira-se à articulação do Telessaúde com a rede e com a regulação das suas ofertas assistenciais. Nas portarias no 2.859 e 2.860 do Telessaúde destacam-se incentivos financeiros que buscam ampliar a utilização do Telessaúde pelas equipes da APS e sua participação em linhas de cuidado ou como parte do acesso a especialidades consideradas prioritárias, incluindo a adoção de protocolos pactuados com as centrais de regulação

No Manual do Telessaúde é possível destacar que, junto à qualificação da APS, defende-se a integração dos NTS (Núcleos Técnicos de Telessaúde) aos processos regulatórios como forma de gerar encaminhamentos mais adequados, qualificando 
o acesso à Atenção Especializada. Fala-se em evitar encaminhamentos de casos que poderiam ser resolvidos na APS. Aborda, ainda, diferentes desenhos de integração possíveis e existentes entre telessaúde e regulação.

Na PNAB 2017 é afirmado que a gestão municipal deve criar condições para que o acesso aos serviços especializados ambulatoriais seja realizado preferencialmente pela APS. Coloca como responsabilidade da APS a ordenação dos fluxos nos demais pontos de atenção da RAS, gestão da referência e contrarreferência e estabelecimento de relação com os especialistas que cuidam das pessoas do seu território. Além disso, atribui funçóes na regulação a todos os profissionais das equipes da APS.

O quadro 3 sintetiza os principais elementos de organização e gestão da regulação apresentados.

Quadro 3. Organização e gestão da regulação nas políticas nacionais de saúde de 2002 a 2017

\begin{tabular}{|c|c|c|c|}
\hline Documento & $\begin{array}{c}\text { Ano de } \\
\text { publicaçáo }\end{array}$ & $\begin{array}{c}\text { Principais formulaçóes sobre } \\
\text { organização e gestáo da } \\
\text { regulaçáo }\end{array}$ & $\begin{array}{l}\text { Lugar da APS na organizaçáo e } \\
\text { gestáo da regulação }\end{array}$ \\
\hline NOAS & 2002 & $\begin{array}{l}\text { Apresenta a delegação ao } \\
\text { médico regulador, pelo gestor } \\
\text { competente, de autoridade } \\
\text { sanitária, para que exerça } \\
\text { responsabilidade sobre a } \\
\text { regulação da assistência. }\end{array}$ & $\begin{array}{l}\text { Amplia formalmente as } \\
\text { responsabilidades dos municípios } \\
\text { na APS e busca constituir o } \\
\text { processo de regionalização como } \\
\text { estratégia de hierarquização dos } \\
\text { serviços de saúde e de busca por } \\
\text { maior equidade. }\end{array}$ \\
\hline $\begin{array}{l}\text { Pacto pela } \\
\text { saúde }\end{array}$ & 2006 & $\begin{array}{l}\text { Encarrega os municípios de } \\
\text { executar o controle do acesso } \\
\text { ambulatorial do seu munícipio, } \\
\text { que pode ser feito por meio de } \\
\text { centrais de regulaçáo. Também } \\
\text { ficam responsáveis por operar o } \\
\text { complexo regulador dos serviços } \\
\text { presentes no seu território, } \\
\text { realizando a cogestão com o } \\
\text { Estado e outros municípios das } \\
\text { referências intermunicipais. }\end{array}$ & $\begin{array}{l}\text { Municipaliza organização e } \\
\text { pactuação do acesso a ações e } \\
\text { serviços especializados a partir da } \\
\text { APS, pela integraçáo e articulação } \\
\text { entre os níveis do sistema com } \\
\text { base na Programação Pactuada } \\
\text { Integrada (PPI). }\end{array}$ \\
\hline
\end{tabular}

continua... 


\begin{tabular}{|c|c|c|c|}
\hline Documento & $\begin{array}{c}\text { Ano de } \\
\text { publicaçáo }\end{array}$ & $\begin{array}{c}\text { Principais formulaçóes sobre } \\
\text { organizaçáo e gestáo da } \\
\text { regulaçáo }\end{array}$ & $\begin{array}{l}\text { Lugar da APS na organização e } \\
\text { gestáo da regulaçáo }\end{array}$ \\
\hline PNAB & 2006 & $\begin{array}{l}\text { Não apresenta elementos sobre } \\
\text { a organização e gestão geral da } \\
\text { regulaçấo. }\end{array}$ & $\begin{array}{l}\text { Coloca-se, entre as ações } \\
\text { necessárias da atençáo primária, } \\
\text { a garantia de fluxos de referência } \\
\text { e contrarreferência aos serviços } \\
\text { especializados. }\end{array}$ \\
\hline $\begin{array}{l}\text { Política } \\
\text { Nacional de } \\
\text { Regulaçáo }\end{array}$ & 2008 & $\begin{array}{l}\text { Define os modelos de estrutura } \\
\text { e abrangência dos complexos } \\
\text { reguladores estaduais, regionais } \\
\text { e municipais, que devem ser } \\
\text { pactuados entre os gestores, além } \\
\text { das atividades a serem exercidas } \\
\text { pelo Ministério da Saúde. }\end{array}$ & $\begin{array}{l}\text { Poucas menções ao lugar da } \\
\text { atenção primária na organização e } \\
\text { gestão da regulação. Municipaliza } \\
\text { a responsabilidade de viabilizar o } \\
\text { processo de regulação do acesso } \\
\text { a partir da Atenção Básica, } \\
\text { provendo capacitação, ordenação } \\
\text { de fluxo, aplicação de protocolos } \\
\text { e informatização. }\end{array}$ \\
\hline $\begin{array}{l}\text { Diretrizes } \\
\text { para a } \\
\text { implantação } \\
\text { de complexos } \\
\text { reguladores }\end{array}$ & 2010 & $\begin{array}{l}\text { Detalha a estruturaçáo } \\
\text { do complexo regulador, } \\
\text { especificando desde seu quadro } \\
\text { profissional até detalhes } \\
\text { da infraestrutura mínima } \\
\text { necessária para implantaçáo e } \\
\text { funcionamento adequado. }\end{array}$ & $\begin{array}{l}\text { Defende organizar uma atenção } \\
\text { primária resolutiva pelos } \\
\text { municípios, que faça solicitações } \\
\text { padronizadas pelos protocolos aos } \\
\text { outros níveis de complexidade. }\end{array}$ \\
\hline PNAB & 2011 & $\begin{array}{l}\text { Concebe práticas de regulação } \\
\text { realizadas na APS, articuladas } \\
\text { com os processos regulatórios } \\
\text { realizados em outros espaços da } \\
\text { rede, sem detalhar elementos } \\
\text { organizativos e de gestáo para isso. }\end{array}$ & $\begin{array}{l}\text { Aponta a atenção primária como } \\
\text { coordenadora do cuidado e } \\
\text { ordenadora das redes, atuando } \\
\text { como centro de comunicação } \\
\text { entre os pontos de atenção. }\end{array}$ \\
\hline $\begin{array}{l}\text { Portaria } \\
\mathrm{n}^{\circ} 2.554- \\
\text { Telessaúde }\end{array}$ & 2011 & $\begin{array}{l}\text { Prevê genericamente a articulaçáo } \\
\text { do Telessaúde com a rede e com a } \\
\text { Regulaçao do acesso aos serviços }\end{array}$ & $\begin{array}{l}\text { Busca pelo aumento da capacidade } \\
\text { resolutiva da APS por meio de } \\
\text { diferentes açóes de Telessaúde. }\end{array}$ \\
\hline $\begin{array}{l}\text { Portarias } \mathrm{n}^{\circ} \\
2.859 \text { e } 2.860 \\
\text { - Telessaúde }\end{array}$ & 2014 & $\begin{array}{l}\text { Preveem foco parcial do } \\
\text { Telessaúde em especialidades e } \\
\text { linhas de cuidado prioritárias, } \\
\text { e indicam a necessidade de os } \\
\text { Núcleos de Telessaúde pactuarem } \\
\text { protocolos de encaminhamento } \\
\text { com as Centrais de Regulaçao. }\end{array}$ & $\begin{array}{l}\text { Definem números de referência } \\
\text { para teleconsultoria segundo } \\
\text { equipes de APS, com indução } \\
\text { indireta à realização de } \\
\text { teleconsultorias relacionadas } \\
\text { a linhas de cuidado ou } \\
\text { especialidades prioritárias. }\end{array}$ \\
\hline
\end{tabular}




\begin{tabular}{|c|c|c|c|}
\hline Documento & $\begin{array}{c}\text { Ano de } \\
\text { publicaçáo }\end{array}$ & $\begin{array}{c}\text { Principais formulaçóes sobre } \\
\text { organização e gestão da } \\
\text { regulaçáo }\end{array}$ & $\begin{array}{l}\text { Lugar da APS na organizaçáo e } \\
\text { gestáo da regulaçáo }\end{array}$ \\
\hline $\begin{array}{l}\text { Manual } \\
\text { Instrutivo } \\
\text { Telessaúde }\end{array}$ & 2015 & $\begin{array}{l}\text { Defende a integraçáo dos NTS } \\
\text { (Núcleos Técnicos de Telessaúde) } \\
\text { aos processos regulatórios para } \\
\text { qualificar o acesso à Atenção } \\
\text { Especializada. Apresenta vários } \\
\text { desenhos para a discussão e a } \\
\text { operacionalização da integração } \\
\text { do Telessaúde e da Regulação. }\end{array}$ & $\begin{array}{l}\text { Defende a integração entre } \\
\text { Telessaúde e regulação como } \\
\text { potencial nova interface entre } \\
\text { APS e processos regulatórios, } \\
\text { mediada por componentes } \\
\text { pedagógicos e técnicos com } \\
\text { implicação assistencial. }\end{array}$ \\
\hline PNAB & 2017 & $\begin{array}{l}\text { Atribui funções na regulação a } \\
\text { todos os profissionais das equipes } \\
\text { da atenção primária. } \\
\text { Coloca como responsabilidade } \\
\text { da APS: a ordenação dos } \\
\text { fluxos nos demais pontos de } \\
\text { atenção da RAS, a gestão da } \\
\text { referência e contrarreferência, o } \\
\text { estabelecimento de relação com } \\
\text { os especialistas que cuidam das } \\
\text { pessoas do seu território. }\end{array}$ & $\begin{array}{l}\text { Afirma que a gestão municipal } \\
\text { deve criar condiçóes para que o } \\
\text { acesso aos serviços especializados } \\
\text { ambulatoriais ocorra } \\
\text { preferencialmente pela atenção } \\
\text { primária. }\end{array}$ \\
\hline
\end{tabular}

Fonte: elaborado pelos autores

\section{Estratégias e ferramentas de regulaçáo assistencial}

A NOAS 2002 prevê a configuração de complexos reguladores mas não chega a ofertar ferramentas de regulação. O Pacto pela Saúde também coloca os complexos reguladores como uma das principais estratégias de regulação e vai além, citando outras estruturas e níveis de atenção com os quais o complexo deve se articular e o grau de abrangência que deve ter, considerando as três esferas de gestáo do SUS. $\mathrm{O}$ documento não chega a ofertar ferramentas de regulação, assim como a PNAB 2006 não o faz.

Dentre as estratégias e ferramentas da Política Nacional de Regulação, de 2008, destacam-se o controle das agendas de consultas e procedimentos especializados, a padronização das solicitaçóes de procedimentos por meio dos protocolos assistenciais e o estabelecimento de referências entre unidades de diferentes níveis de complexidade, de abrangência local, intermunicipal e interestadual, segundo fluxos e protocolos pactuados. 
O documento Diretrizes para implantação de complexos reguladores é o que mais detalha ferramentas de regulação. A ação regulatória envolve, segundo ele, o levantamento e a distribuição de cotas de procedimentos realizados pelos estabelecimentos executantes para os estabelecimentos solicitantes, o processo de autorização prévio à execução da ação ou serviço e a execução da ação regulatória feita por profissional competente, capaz de análise crítica e discernimento que o conduzam às decisóes baseadas em protocolos de regulação. Para implantar/implementar a Regulação da Atenção à Saúde, o Ministério da Saúde definiu três eixos: Recursos financeiros para a implantação dos Complexos Reguladores, Instrumentos para operacionalização dos Complexos Reguladores e Programa de capacitação permanente de recursos humanos.

Segundo o documento, a açáo regulatória deve estar fundamentada em protocolos de encaminhamento, que são instrumentos ordenadores dos diversos níveis de complexidade da atenção, e em protocolos clínicos, que tratam da forma de intervenção por patologia, subsidiando as decisôes terapêuticas. Realizada por equipe de médicos, a autorização de procedimentos pode ou não ser prévia, baseada nos protocolos preestabelecidos, utilizando o mecanismo de cotização da oferta de serviços disponibilizada para as unidades solicitantes e executantes da central.

O SISREG, software de regulação disponibilizado pelo Ministério da Saúde, é adotado como um instrumento estratégico para a regulação, que subsidia também as áreas de controle, avaliação, planejamento e gestâo, auxiliando gestores na tomada de decisão. A parametrização de suas funcionalidades permite, também, a adequação das às peculiaridades locais.

Na PNAB 2011, algumas ferramentas e dispositivos para a organização do fluxo dos usuários são destacadas: a gestão das listas de espera (encaminhamentos para consultas especializadas, procedimentos e exames), prontuário eletrônico em rede, protocolos de atenção organizados sob a lógica de linhas de cuidado, discussão e análise de casos traçadores, eventos-sentinela e incidentes críticos, entre outros. O Telessaúde, a integração dos sistemas de informação e a Política Nacional de Regulação também são valorizados para a continuidade do cuidado do usuário que precisa de atenção especializada.

Além de informatizar as unidades básicas de saúde, a portaria no 2.554 , de 2011, apresenta como ferramentas a elaboração de fluxos e protocolos clínicos que incluam a solicitação prévia de segunda opiniâo formativa e/ou teleconsultoria antes do encaminhamento ou da solicitação para a central de regulação. 
As portarias $\mathrm{n}^{\circ} 2.859$, e no 2.860 , de 2014, definem componentes fixos e variáveis no custeio dos núcleos de Telessaúde, sendo que o valor do componente variável fica condicionado à definição e pactuação de linhas de cuidado e/ou especialidades prioritárias e seus respectivos protocolos de encaminhamento.

O documento Custeio dos Núcleos de Telessaúde Brasília - Manual instrutivo, de 2015, considera que os protocolos de regulaçáo do acesso ou protocolos de encaminhamento são ferramentas de gestão que têm por objetivo responder a questôes relativas à indicação clínica, à qualidade do encaminhamento, à continuidade do cuidado e à priorização de casos.

A PNAB 2017 recomenda a implementaçáo de processos que aumentem a capacidade resolutiva da APS, bem como sua comunicação com centrais de regulação e serviços especializados. Sáo destacadas ferramentas de Telessaúde articuladas às decisôes clínicas e aos processos de regulação do acesso, além da utilização de protocolos de encaminhamentos para servir de orientação aos profissionais. São também retomadas as práticas de microrregulação nas UBS, gestão de filas de espera, exames e consultas descentralizados, apoio matricial presencial e/ou a distância, dentre outros. O quadro IV reúne as principais estratégias e ferramentas identificadas.

Quadro 4. Estratégias e ferramentas de regulação nas políticas nacionais de saúde de 2002 a 2017

\begin{tabular}{|l|l|l|l|}
\hline Documento & $\begin{array}{c}\text { Ano de } \\
\text { publicaçáo }\end{array}$ & \multicolumn{1}{|c|}{$\begin{array}{c}\text { Principais estratégias e } \\
\text { ferramentas }\end{array}$} & $\begin{array}{c}\text { Lugar da APS em interface com } \\
\text { a ferramenta e/ou estratégia } \\
\text { citada }\end{array}$ \\
\hline NOAS & 2002 & $\begin{array}{l}\text { Define que a regulaçáo deverá ser } \\
\text { efetivada por meio de complexos } \\
\text { reguladores. }\end{array}$ & $\begin{array}{l}\text { Não apresenta elementos acerca } \\
\text { do lugar da APS em interface com } \\
\text { os complexos reguladores. }\end{array}$ \\
\hline $\begin{array}{l}\text { Pacto pela } \\
\text { saúde }\end{array}$ & $\begin{array}{l}\text { Apresenta os complexos } \\
\text { reguladores como uma das } \\
\text { principais estratégias de regulação } \\
\text { e cita outras estruturas e níveis de } \\
\text { atençáo com os quais o complexo } \\
\text { deve se articular. Orienta sobre sua } \\
\text { implementação, monitoramento e } \\
\text { o grau de abrangência estes devem } \\
\text { ter, considerando as três esferas de } \\
\text { gestáo do SUS. }\end{array}$ & $\begin{array}{l}\text { Não apresenta elementos acerca } \\
\text { do lugar da APS em interface com } \\
\text { os complexos reguladores. }\end{array}$ \\
\hline
\end{tabular}

continua... 


\begin{tabular}{|c|c|c|c|}
\hline Documento & $\begin{array}{c}\text { Ano de } \\
\text { publicaçáo }\end{array}$ & $\begin{array}{c}\text { Principais estratégias e } \\
\text { ferramentas }\end{array}$ & $\begin{array}{c}\text { Lugar da APS em interface com } \\
\text { a ferramenta e/ou estratégia } \\
\text { citada }\end{array}$ \\
\hline PNAB & 2006 & $\begin{array}{l}\text { Não apresenta ferramentas de } \\
\text { regulação. }\end{array}$ & $\begin{array}{l}\text { Define a atençáo básica } \\
\text { estrategicamente como porta de } \\
\text { entrada preferencial do sistema e } \\
\text { como coordenadora do cuidado. }\end{array}$ \\
\hline $\begin{array}{l}\text { Política } \\
\text { Nacional de } \\
\text { Regulação }\end{array}$ & 2008 & $\begin{array}{l}\text { Aponta que a regulação do } \\
\text { acesso será estabelecida mediante } \\
\text { Complexos Reguladores, formados } \\
\text { por centrais de regulação, } \\
\text { preferencialmente, descentralizadas } \\
\text { e com um nível central de } \\
\text { coordenação e integração. }\end{array}$ & $\begin{array}{l}\text { Responsabiliza os municípios } \\
\text { na viabilização do processo de } \\
\text { regulação do acesso a partir da } \\
\text { APS, provendo capacitação, } \\
\text { ordenação do fluxo, aplicação de } \\
\text { protocolos e informatização. }\end{array}$ \\
\hline $\begin{array}{l}\text { Diretrizes } \\
\text { para a } \\
\text { implantação } \\
\text { de complexos } \\
\text { reguladores }\end{array}$ & 2010 & $\begin{array}{l}\text { Apresenta os complexos } \\
\text { reguladores como estratégia para } \\
\text { absorver o fluxo da assistência } \\
\text { na rede, adequando a oferta } \\
\text { à demanda. Fundamenta a } \\
\text { ação regulatória em protocolos } \\
\text { clínicos e de encaminhamento. } \\
\text { O SISREG é abordado como um } \\
\text { instrumento estratégico. }\end{array}$ & $\begin{array}{l}\text { Define os complexos reguladores } \\
\text { como estruturas compostas por } \\
\text { centrais e redes redes de serviços } \\
\text { de saúde organizados a partir da } \\
\text { APS }\end{array}$ \\
\hline PNAB & 2011 & $\begin{array}{l}\text { Destaca para a organização do } \\
\text { fluxo dos usuários: gestão das listas } \\
\text { de espera; prontuário eletrônico } \\
\text { em rede; protocolos de atenção } \\
\text { organizados sob a lógica de linhas } \\
\text { de cuidado; discussão e análise de } \\
\text { casos traçadores, eventos sentinela } \\
\text { e incidentes críticos; o Telessaúde, } \\
\text { entre outros. }\end{array}$ & $\begin{array}{l}\text { Aposta-se na capacidade } \\
\text { resolutiva da APS e na qualidade } \\
\text { da microrregulaçáo realizada } \\
\text { pelos seus profissionais. }\end{array}$ \\
\hline $\begin{array}{l}\text { Portaria } \\
\mathrm{n}^{\circ} 2.554 \text { - } \\
\text { Telessaúde }\end{array}$ & 2011 & $\begin{array}{l}\text { Propõe a informatização das } \\
\text { unidades básicas de saúde. Orienta } \\
\text { a elaboração de fluxograma e de } \\
\text { protocolos clínicos que incluam } \\
\text { a segunda opinião formativa e/ } \\
\text { ou teleconsultoria antes do } \\
\text { encaminhamento ou da solicitação } \\
\text { para a central de regulação. }\end{array}$ & $\begin{array}{l}\text { Objetiva ampliar a resolutividade } \\
\text { da APS e promover sua integraçáo } \\
\text { com o conjunto da RAS. }\end{array}$ \\
\hline
\end{tabular}

continua... 


\begin{tabular}{|c|c|c|c|}
\hline Documento & $\begin{array}{c}\text { Ano de } \\
\text { publicaçáo }\end{array}$ & $\begin{array}{l}\text { Principais estratégias e } \\
\text { ferramentas }\end{array}$ & $\begin{array}{l}\text { Lugar da APS em interface com } \\
\text { a ferramenta e/ou estratégia } \\
\text { citada }\end{array}$ \\
\hline $\begin{array}{l}\text { Portarias } \mathrm{n}^{\circ} \\
2.859 \text { e } 2.860\end{array}$ & 2014 & $\begin{array}{l}\text { Condiciona o valor do componente } \\
\text { de financiamento variável à } \\
\text { pactuaçáo de linhas de cuidado } \\
\text { e/ou especialidades prioritárias } \\
\text { e seus respectivos protocolos de } \\
\text { encaminhamento, bem como à } \\
\text { produçáo de teleconsultorias no } \\
\text { mês por equipe. }\end{array}$ & $\begin{array}{l}\text { Define-se a diferença entre os } \\
\text { portes de Telessaúde, que está } \\
\text { relacionada ao número de equipes } \\
\text { de APS participantes. }\end{array}$ \\
\hline $\begin{array}{l}\text { Manual } \\
\text { Instrutivo } \\
\text { Telessaúde }\end{array}$ & 2015 & $\begin{array}{l}\text { Apresenta protocolos de regulaçáo } \\
\text { do acesso ou protocolos de } \\
\text { encaminhamento. } \\
\text { Aponta o programa Telessaúde } \\
\text { como uma estratégia para } \\
\text { a melhoria da regulação, } \\
\text { qualificando equipes através de } \\
\text { teleconsultorias e tele-educaçáo, } \\
\text { apoiando a tomada de decisão } \\
\text { clínica e gerencial no SUS. }\end{array}$ & $\begin{array}{l}\text { Orienta que se evitem } \\
\text { encaminhamentos de casos que } \\
\text { poderiam ser resolvidos na APS, } \\
\text { apostando no seu potencial } \\
\text { resolutivo. }\end{array}$ \\
\hline PNAB & 2017 & $\begin{array}{l}\text { Destacam-se ferramentas } \\
\text { de Telessaúde articuladas às } \\
\text { decisões clínicas e aos processos } \\
\text { de regulação do acesso, além } \\
\text { da utilização de protocolos de } \\
\text { encaminhamentos. Também } \\
\text { prevê fortalecimento de práticas } \\
\text { de microrregulaçáo nas UBS, } \\
\text { gestáo de filas de espera, exames } \\
\text { e consultas descentralizados, } \\
\text { apoio matricial presencial e/ou a } \\
\text { distância, dentre outros. }\end{array}$ & $\begin{array}{l}\text { Recomenda a articulação e } \\
\text { implementação de processos } \\
\text { que aumentem a capacidade } \\
\text { resolutiva da APS, bem } \\
\text { como sua comunicação com } \\
\text { centrais de regulação e serviços } \\
\text { especializados. }\end{array}$ \\
\hline
\end{tabular}

Fonte: elaborado pelos autores

\section{Discussão}

Em termos de conceitos e noçóes relacionados à regulação do acesso, pode-se ver, desde a NOAS, uma concepçáo abrangente, na qual elementos como acesso adequado e oportuno são evidentes, além de equidade, detalhando-se ainda mais a partir do Pacto pela Saúde. Ressalte-se a diferença do Brasil em relação a experiências 
internacionais, como a da Espanha e de outros países com sistema universal, nos quais fala-se em gestão de listas de espera, não se utilizando a noção de regulação assistencial ou do acesso (CONILL et al., 2011; ALMEIDA et al., 2013). No processo brasileiro, fica evidente também o predomínio do regime governamental de regulação (CECILIO et al., 2014), ainda que a figura do médico regulador esteja num lugar intermediário, entre a gestão e o território profissional.

A APS é frequentemente citada (como um espaço estratégico e estruturante da rede), e chama a atenção o enriquecimento conceitual da regulação operado a partir da PNAB de 2011, aportando a noção de microrregulação ao mesmo tempo em que reivindica um lugar de protagonismo e não apenas de consumidora dos processos centralizados de regulação. Este movimento deu-se numa conjuntura de inflexão da PNAB (MELO et al., 2018). Por um lado, este destaque maior para a regulação na APS avança em termos da sua capacidade de gestáo do cuidado e no reconhecimento e desenvolvimento mais formal do regime profissional de regulação (CECILIO et al., 2014). Por outro, requer diferenciação e cuidado com o que tem sido pensado para a saúde suplementar e operado no campo da atenção gerenciada, em que se reconhece o caráter estratégico das decisôes profissionais para, frequentemente, buscar controlá-las a partir de mecanismos gerenciais racionalizadores, que imprimem uma tensão entre lógica financeira e lógica do cuidado (IRIART et al., 2000; MALTA et al., 2004; UGÁ et al., 2009).

Os elementos organizativos e de gestáo observados evidenciam a necessária contextualização da regulação no âmbito do complexo processo de construção de redes de atenção regionalizadas e de articulação interfederativa que marcam a construção de um sistema público e universal num país diverso, desigual e de dimensóes continentais como o Brasil, constrangido por subfinanciamento crônico, por difíceis interfaces público-privadas e por frágil sustentabilidade política (PAIM, 2018). Sem isto, a regulação pode se limitar a uma "regulação da escassez", restringindo-se a atuar sobre a oferta de procedimentos e sobre as decisóes profissionais sem enfrentar, de modo consistente, nós críticos do acesso e da conformação da atenção especializada (SOLLA; REIS, 2008; ROCHA, 2014; TESSER; POLI, 2017).

Destaque deve ser dado, neste sentido, ao desenvolvimento dos complexos reguladores com centrais focadas em diferentes âmbitos da atenção (ambulatorial, leitos, urgências e emergências), e da articulação do seu funcionamento com os processos de pactuação, programação, controle e avaliação, sem os quais se desconsideraria, a priori, 
a dimensão sistêmica e processual da regulação, assim como seus condicionantes. Isto, aliado a uma visão abrangente de rede (não apenas como recursos, mas também como interdependência e interação) é fundamental para que não se opere uma regulação sem sintonia com os princípios e a realidade do SUS, e para que haja clareza sobre o modelo tecnoassistencial que esta busca reforçar ou combater (FERREIRA, 2010).

Nesta arquitetura organizacional, a APS não parece ocupar lugar de destaque, na medida em que as decisóes tendem a se concentrar em torno de ofertas controladas pelas centrais de regulação, em que pese o reconhecimento dado à APS e à sua capacidade resolutiva. A agenda de articulação entre Telessaúde e regulação mostrase, por sua vez, como uma espécie de dispositivo concreto produzido desde a gestáo federal da APS que busca incidir sobre a organização e funcionamento da regulação do acesso (no âmbito ambulatorial), aproximando-as da APS e ao mesmo tempo tensionando-a para ampliar sua capacidade clínica. Esta articulação, embora não possua o grau de proximidade e de interação entre atenção especializada e APS defendido por alguns autores (ALBIERI; CECILIO, 2015; BADUY, 2011; GIANNOTTI, 2013), pode ir além do contato limitado às solicitaçôes escritas e à sua autorização ou devolução (comuns nas centrais de regulação), a depender de como os processos formativos dos trabalhadores (notadamente dos médicos), via telessaúde, forem conectados à pactuação de fluxos assistenciais e ao processo de regulação do acesso a exames e consultas especializadas.

Sobre as estratégias e ferramentas de regulação, que em parte se confundem com sua organização, ora são desdobramentos operacionais, ora são artifícios criados para viabilizar ou fazer avançarem os processos regulatórios. Neste sentido, merecem destaque as Diretrizes para os Complexos Reguladores, cujo conteúdo revela o grau de densidade e detalhamento que o campo da regulação assistencial assumiu, com variados saberes e ferramentas, incluindo as de informática. Isto, no entanto, não deve confundir regulação com sistema logístico ou de informação, pois seria um erro ignorar as tensóes e disputas, em torno de decisôes sobre disponibilização e uso de recursos assistenciais, que atravessam profundamente os processos regulatórios (CECILIO, 2014). Talvez a noção de tecnologia de gestáo ou de "saber tecnológico" (MENDES-GONÇALVES, 1994) seja apropriada para definir a inteligência de regulação assistencial desenvolvida no SUS.

O movimento correlato na APS, por sua vez, em grande parte vinculado à interface entre Telessaúde e regulação, conferiu maior visibilidade ao tema dos 
protocolos de encaminhamento, a serem utilizados no bojo de uma estratégia que buscou incentivar o uso do Telessaúde vinculando-o ao acesso dos usuários a serviços especializados. Apesar de sua importância (como guias apoiadores à tomada de decisóes clínicas e aos fluxos assistenciais entre serviços) cabe assinalar que os protocolos não substituem a necessária interação entre profissionais generalistas e especialistas. Há que se ter cautela, ainda, com a utilização do telessaúde como pré-requisito incondicional para o encaminhamento de usuários a outros serviços, sob pena de se configurar uma nova burocratização e barreira de acesso, quando o que precisamos parece ser mais uma regulação viva e centrada nas necessidades dos usuários mais do que em normas e procedimentos (BATISTA et al., 2019).

Não tiveram o mesmo destaque que os protocolos de encaminhamento, no entanto, movimentos de integração e interoperabilidade entre os sistemas de informação da APS e os da regulação, nem iniciativas mais estruturadas conferindo poder regulatório aos profissionais da APS, essenciais para práticas como a gestão de listas de espera e para a coordenaçáo do cuidado (CONILL et al., 2011; ALMEIDA et al., 2013). Para isso talvez seja necessário reconectar estas iniciativas com a construção das redes regionais, buscando auxiliar no enfrentamento dos seus condicionantes.

\section{Considerações finais}

Este estudo caracterizou a trajetória das formulaçôes e iniciativas de regulação do acesso operadas desde as políticas nacionais entre os anos de 2002 e 2017, bem como suas interfaces com a APS. Observou-se um movimento de ampliação da participação da APS na regulação assistencial, traduzido conceitualmente na noção de microrregulação e operacionalmente em iniciativas de articulação entre Telessaúde e regulação. $\mathrm{O}$ reconhecimento desta direção, no entanto, não significa a sua efetivação nas realidades locais, e requer atenção aos condicionantes da constituição das redes de atenção e das necessárias coordenação e continuidade do cuidado nas regiōes de saúde do país. Ainda que tenha o limite de basear-se em documentos formais de políticas (que são sabidamente apenas uma das suas faces), o estudo evidencia alcances e limites das interfaces entre regulação do acesso e APS até então formuladas, bem como a necessidade de novas intervençôes e investigaçóes neste campo. ${ }^{1}$

\section{Agradecimento}

Ao Programa Inova Fiocruz. 


\section{Referências}

ALBIERI, F. A. O.; CECILIO, L. C. de O. De frente com os médicos: uma estratégia comunicativa de gestáo para qualificar a regulação do acesso ambulatorial. Saúde em debate, Rio de Janeiro, v. 39, n. esp, p. 184-195, 2015.

ALMEIDA, P. F. de et al. Estratégias de integração entre atenção primária à saúde e atenção especializada: paralelos entre Brasil e Espanha. Saúde em debate, Rio de Janeiro, v. 37, n. 98, p. 400-415, set. 2013.

BADUY, R. S. et al. A regulação assistencial e a produção do cuidado: um arranjo potente para qualificar a atenção. Cad. Saúde Pública, Rio de Janeiro, v. 27, n. 2, p. 295-304, 2011.

BARBOSA, D. V. S.; BARBOSA, N. B.; ESTELA, N. Regulação em Saúde: desafios à governança do SUS. Cad Saúde Colet. Rio de Janeiro, v. 24, n. 1, p. 49-54, 2016.

BATISTA, S. R. et al. O Complexo Regulador em Saúde do Distrito Federal, Brasil, e o desafio da integração entre os níveis assistenciais. Ciênc. saúde coletiva, Rio de Janeiro, v. 24, n. 6, p. 2043-2052, jun. 2019.

. Ministério da Saúde. Secretaria de Atenção à Saúde. Departamento de Regulação, Avaliação e Controle de Sistemas. Diretrizes para a implantação de complexos reguladores. 2.ed. - Brasília, DF: Editora do Ministério da Saúde, 2010 (Série A. Normas e Manuais Técnicos) (Série Pactos pela Saúde 2006; v. 6).

Ministério da Saúde. Portaria GM no 373, de 27 de fevereiro de 2002. Aprova, na forma do anexo desta portaria, a norma operacional da Assistência à saúde - NOAS-SUS 01/2002 que amplia as responsabilidades dos municípios na atenção básica; estabelece o processo de regionalização como estratégia de hierarquização dos serviços de saúde e de busca de maior equidade; cria mecanismos para o fortalecimento da capacidade de gestáo do sistema único de saúde e procede a atualização dos critérios de habilitação de estados e municípios. Brasília, 2002.

. Ministério da Saúde. Portaria no 399, de 22 de fevereiro de 2006. Divulga o Pacto pela Saúde 2006 - Consolidação do SUS e aprova as Diretrizes Operacionais do Referido Pacto. Brasília, 2006.

. Ministério da Saúde. Portaria $n^{\circ}$ 648, de 28 de março de 2006. Política Nacional de Atenção Básica. Brasília, 2006.

. Ministério da Saúde. Portaria no 2.436, de 21 de setembro de 2017. Aprova a Política Nacional de Atenção Básica, estabelecendo a revisão de diretrizes para a organização da Atenção Básica, no âmbito do Sistema Único de Saúde (SUS). Brasília, 2017.

- Ministério da Saúde. Portaria no 2.488, de 21 de outubro de 2011. Aprova a Política Nacional de Atenção Básica, estabelecendo a revisão de diretrizes e normas para a organizaçáo 
da Atenção Básica, para a Estratégia Saúde da Família (ESF) e o Programa de Agentes Comunitários de Saúde (PACS). Brasília, 2011.

. Ministério da Saúde. Portaria no 2.554, de 27 de outubro de 2011. Institui, no Programa de Requalificação de Unidades Básicas de Saúde, o Componente de Informatização e Telessaúde Brasil Redes na Atenção Básica, integrado ao Programa Nacional Telessaúde Brasil Redes. Brasília, 2011.

Ministério da Saúde. Portaria $n^{\circ}$ 2.859, de 29 de dezembro de 2014. Institui o incentivo financeiro de custeio mensal destinado aos Núcleos Intermunicipais e Estaduais de Telessaúde do Programa Nacional de Telessaúde Brasil Redes na Atenção Básica, e dá outras providências. Brasília, 2014.

. Ministério da Saúde. Portaria n ${ }^{\circ} 2.860$, de 29 de dezembro de 2014. Define os valores do incentivo financeiro de custeio mensal destinado aos Núcleos de Telessaúde do Programa Nacional Telessaúde Brasil Redes na Atenção Básica de que trata a Portaria nº 2.859/GM/MS, de 29 de dezembro de 2014. Brasília, 2014.

. Ministério da Saúde. Portaria $n^{\circ} 4.279$, de 30 de dezembro de 2010. Estabelece diretrizes para a organização da Rede de Atenção à saúde no âmbito do sistema único de saúde. Brasília, 2010.

. Ministério da Saúde. Secretaria de Atenção à Saúde. Portaria GM no 1559, de $1^{\circ}$ de agosto de 2008. Institui a Política Nacional de Regulação do Sistema Único de Saúde. Brasília, 2008.

. Ministério da Saúde. Secretaria de Atenção à Saúde. Secretaria de Gestão do Trabalho e Educação na Saúde. Custeio dos Núcleos de Telessaúde: manual instrutivo [recurso eletrônico]. Brasília: Ministério da Saúde; 2015.

CAMPOS, G. W. S.; DOMITTI, A. C. Apoio matricial e equipe de referência: uma metodologia para gestão do trabalho interdisciplinar em saúde. Cad. Saúde Pública, Rio de Janeiro, v. 23, n. 2, p. 399-407, fev. 2007.

CECILIO L. C. O. et al. Os mapas do cuidado: o agir leigo na saúde. São Paulo: Editora Hucitec, Fapesp, 2014.

CONILL, E. M.; GIOVANELLA, L.; ALMEIDA, P. F. Listas de espera em sistemas públicos: da expansão da oferta para um acesso oportuno? Consideraçóes a partir do Sistema Nacional de Saúde espanhol. Ciênc. saúde coletiva, Rio de Janeiro, v. 16, n. 6, p. 2783-2794, jun. 2011.

FAUSTO, M. et al. A posição da Estratégia Saúde da Família na rede de atenção à saúde na perspectiva das equipes e usuários participantes do PMAQ-AB. Saúde em debate, Rio de Janeiro, v 38, p. 13-33, 2014.

FERREIRA, J. B. B. et al. O complexo regulador da assistência à saúde na perspectiva de seus sujeitos operadores. Interface (Botucatu), Botucatu, v. 14, n. 33, p. 345-358, jun. 2010. 
GIANNOTTI, E. M. A organização de processos regulatórios na gestão municipal de saúde e suas implicaçóes no acesso aos serviços: um estudo de caso do município de Guarulhos. Dissertação (Mestrado em Serviços de Saúde Pública) - Faculdade de Saúde Pública, Universidade de São Paulo, São Paulo, 2013.

GRIMSHAW, J. M. et al. Intervenciones para mejorar las derivaciones de pacientes ambulatorios desde la atención primaria a la atención secundaria (Revisión Cochrane traducida). La Biblioteca Cochrane Plus, n. 4, 2008.

KRIPKA R. M. L.; SCHELLER M.; BONOTTO D. Pesquisa Documental: consideraçóes sobre conceitos e características na Pesquisa Qualitativa. Investigação Qualitativa em Educação. Atas CIAIQ, v. 2, p. 243-247, 2015.

IRIART, C.; MERHY E. E.; WAITZKIN, H. La atención gerenciada en América Latina. Transnacionalización del sector salud en el contexto de la reforma. Cadernos de Saúde Pública, v. 16, n. 1, p. 95-105, 2000.

MAGALHÃES JR, H. M. O desafio de construir e regular redes públicas, com integralidade, em sistemas privado-dependentes: a experiência de Belo Horizonte. Tese (Doutorado em Saúde Coletiva) - Faculdade de Ciências Médicas, Universidade Estadual de Campinas, Campinas. 2006.

MAGALHÃES JR, H. M. Redes de Atenção à Saúde: rumo à integralidade. Saúde em debate, Rio de Janeiro, n. 52, 2014.

MAGALHÂES JR, H. M.; PINTO, H. A. Atenção Básica enquanto ordenadora da rede e coordenadora do cuidado: ainda uma utopia? Saúde em debate, Rio de Janeiro, n. 51, p. 4-7, 2014.

MALTA, D. C. et al. Perspectivas da regulaçáo na saúde suplementar diante dos modelos assistenciais. Ciênc. saúde coletiva, Rio de Janeiro, v. 9, n. 2, p. 433-444, jun. 2004.

MATTOS, R. A.; BAPTISTA, T. W. F. Sobre política (ou o que achamos pertinente refletir para analisar políticas). In: MATTOS, R. A.; BAPTISTA, T. W. F. (Org.). Caminhos para Análise das Políticas de Saúde. Porto Alegre: Editora Rede Unida, 2011. p. 83-149.

MELO, E. A. et al. Mudanças na Política Nacional de Atenção Básica: entre retrocessos e desafios. Saúde em debate; vol. 42, n. spe1, p. 38-51, Rio de Janeiro, 2018.

MENDES, E. V. As redes de atenção à saúde. Ciênc saúde colet. Rio de Janeiro, v. 15, n. 5, p. 2297-2305, 2010.

MENDES-GONÇALVES, R. B. Tecnologia e Organização Social das Práticas de Saúde. São Paulo: Hucitec, 1994.

OLIVEIRA, L. A. et al. Processos microrregulatórios em uma Unidade Básica de Saúde e a produção do cuidado. Saúde em debate, Rio de Janeiro, v. 40, n. 109, p. 8-21, 2016.

OLIVEIRA, R. R. O.; ELIAS, P. E. M. Conceitos de Regulação em Saúde no Brasil. Revista de Saúde Pública, São Paulo, v. 46, n. 3, 2012. 
PAIM, J. S. Sistema Único de Saúde (SUS) aos 30 anos. Ciênc. saúde coletiva, Rio de Janeiro, v. 23, n. 6, p. 1723-1728, jun 2018.

PINTO, L. F et al. A regulação municipal ambulatorial de serviços do Sistema Único de Saúde no Rio de Janeiro: avanços, limites e desafios. Ciênc Saúde Colet, v. 22, n. 4, p. 1257-1267, 2017.

ROCHA, D. C. Gestão do Cuidado na Atenção Especializada: elementos para pensar uma política. Dissertação (mestrado) - Universidade Estadual de Campinas, Departamento de Medicina Preventiva e Social, Campinas, 2014.

SANTOS, F. P.; MERHY E. E. A regulação pública da saúde no Estado brasileiro: uma revisão. Interface, Botucatu, v. 10, n. 19, p. 25-41, 2006.

SOLLA, J.; CHIORO, A. Atenção ambulatorial especializada. In: GIOVANELLA, L. et al. (Org.). Politicas e sistema de saúde no Brasil. Rio de Janeiro: Fiocruz; 2008. p. 627-73.

STARFIELD, B. Atenção Primária - equilíbrio entre necessidades de saúde, serviços e tecnologia. Brasília: UNESCO/Ministério da Saúde, 2002.

TESSER, C. D.; POLI, N. P. Atenção especializada ambulatorial no Sistema Único de Saúde: para superar um vazio. Ciênc saúde colet. Rio de Janeiro, v. 22, n. 3, p. 941-951, 2017.

UGA, M. A. D. et al. Mecanismos de microrregulação aplicados por operadoras de planos de saúde sobre hospitais privados. Rev. Saúde Pública, São Paulo, v. 43, n. 5, p. 832-838, out. 2009. VILARINS, G. C. M.; SHIMIZU, H. E.; GUITIERREZ, M. M. U. A Regulação em Saúde: aspectos conceituais e operacionais. Saúde em Debate. Rio de Janeiro, v. 36, n. 95, p. 640-647. 2012.

\section{Nota}

${ }^{1}$ E. A. Melo e G. G. Gomes: concepção, planejamento, análise e interpretação dos dados; elaboração do rascunho, revisão crítica do conteúdo e aprovação da versão final do manuscrito. J. O. de Carvalho, P. H. B. Pereira e K. P. L. Guabiraba: elaboração do rascunho, revisão crítica do conteúdo; aprovação da versão final do manuscrito. 


\section{Abstract}

\section{Access Regulation to Specialized Outpatient Care and the Primary Health Care in}

\section{National Policies of SUS}

Different formulations have emphasized Primary Health

Care as the preferred gateway to the health system, the basis of care networks and the care coordination function. Access regulation, in turn, has been considered, in Brazil, as a strategy and central technology for network management. This article aimed to characterize how primary care is placed in the national formulations and guidelines on health care regulation of the SUS from 2002 to 2017. The methodology was the documentary analysis, using public domain sources, notably ordinances and technical manuals of the Ministry of Health, organizing the extracted contents in the dimensions "concepts of regulation", "organization and management of regulation" and "strategies and tools of regulation", which sought to characterize the place of primary care. Greater emphasis was given to the interface between health care regulation and primary care from 2011, more prominently in the documents and initiatives related to primary care management than in the specifics of regulation, focusing on the ambulatory dimension of access regulation and in the elaboration of regulation devices based on primary care, highlighting Telehealth.

> Keywords: access regulation, primary health care, health policies. 